\title{
How to Deal with Modern Trends in Poultry Nutrition?
}

\author{
Mohammed Ali Makki Al-Rubaee* \\ Department of Animal Resources, Iraq \\ *Corresponding author: Mohammed Ali Makki Al-Rubaee, Department of Animal Resources, College of Agriculture, Wasit, Iraq
}

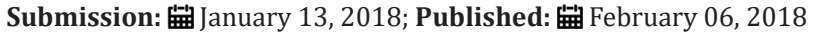

\section{Opinion}

The continuous development in poultry nutrition is a way to keep up with the genetic evolution and to get the most of the genetic ability of the birds. In the last decades a new complex systems were developed to ensure the quality and availability of nutrients in feed and feed stuff, allowing provide the birds with its exact requirements of nutrients.

We are very close from reaching the precise metabolizable energy requirements for the birds at production phase. Super fast growth genetic potentials lead to maximizing diet characteristics to be more suitable for market demands by fixing the maintenance requirements while trying to change or enrich the diet composition of meat and egg which was a difficult target.

The changes in the diet composition is a reflex of the changes in production parameters and production quality, such as the current interest in egg mass as a parallel to egg weight, or the bird's nutrient requirement to reach the optimum immunity not only procuration the simple weight gain or feed conversion ratio.

The pervious goals of feed producers were confined to provide the adequate nutrient content along with minimizing the antinutritional factors. While the modern techniques like Near Infra Red NIR can instantly identify the atypical samples of nutrient complexes, thus, it gave us a huge analytical data to construct a database that would help us making the perfect nutritional decisions in the future.

All of the international poultry producing companies had developed its products to meet the standards of the consuming societies, where the predilction to certain products influenced the diet design to achieve these certain marketing needs.

Most of poultry nutritionists always concentrate on avoiding the natural and artificial anti-nutritional factors who are able to negatively affect bird's and human's health. But the most influential factor in poultry nutrition and production is the limiting or banning of antibiotics in poultry diets. The lack of scientific knowledge result in a wide use of antibiotics in the diets especially the use of water soluble antibiotics producing poultry products loaded with high doses of these compounds, decreasing the consumer acceptance to the products because it's the reason of serious dangers on human's health, but the majority of consumers agreed the minimum doses of antibiotics needed to prevent diseases especially avian flu which can infect the free range chicken.

Many attempt were done to increase the content of unsaturated fatty acids in meat and egg, the fatty acid content in the products is similar to its content in the diet. So we can stuff meat and egg with the desired fatty acid by enriching the diet with it, adding another challenge for feed producers to prevent rancidity. Lately, flaxseed and fish oils were employed in designing modern diets.

The highest cost of the diet components belongs to the energy sources, enormous amounts of corn are used to produce ethanol so its reducing the offered corn quantities for feed production. There is no $100 \%$ successful substitute for corn in poultry diets. The environmental challenge is a limiting factor for poultry industry through the strict methods of poultry feces and litter disposal, leading to more limitations in diet content of phosphor and nitrogen to decrease their levels in feces and reduce ammonia emissions in poultry houses.

We can expect that any extra undigested nutrient will be the food of bacteria, as we know that the digestion capacity in young birds is less than that of adult birds by $20 \%$, and this is what actually happened when presenting broiler's starter diets, the solution came as highly digestible pre-starter diets.

There is a real interest in poultry fiber feeding to enhance GI tract health and its microflora. The significant role of fibers was ignored completely except for overcome the negative effects of Non Starch Polysaccharides NSPs in cereals and reduce viscosity of feces by exogenous enzymes. The variation between advantages and disadvantages of fibers return to its percentage in the diet. Ehe fermentation of NSPs to volatile fatty acids such as butyrate could be a method to control pathogenic microflora. Butyrate from NSPs fermentation is essential in natural growth of epithelial cells.

We must face the truth that the poultry diets are becoming more complicated regarding its credibility and components under imposing quality control rules in feed plants, the train of genetic development will run fast with no stop station in the near future so a decisive decisions must be done take exploit the genetic potential through designing the best diets that can keep up with the market demands. 
Creative Commons Attribution 4.0 International License

Your subsequent submission with Crimson Publishers will attain the below benefits

- High-level peer review and editorial services

- Freely accessible online immediately upon publication

- Authors retain the copyright to their work

- Licensing it under a Creative Commons license

- Visibility through different online platforms

- Global attainment for your research

- Article availability in different formats (Pdf, E-pub, Full Text)

- Endless customer service

- Reasonable Membership services

- Reprints availability upon request

- One step article tracking system 